\title{
Surgical strategies for anomalous origin of the left coronary artery from the right pulmonary artery with an intramural aortic course: A report of 10 cases
}

\author{
Hui Zhang, MD, ${ }^{\mathrm{a}}$ Pei Cheng, MD, ${ }^{\mathrm{b}}$ Ge Jin, MD, ${ }^{\mathrm{b}}$ Ding Han, MD, ${ }^{\mathrm{c}}$ Yi Luo, MD, ${ }^{\mathrm{a}}$ and Jia Li, MD, PhD ${ }^{\mathrm{d}}$
}

\section{ABSTRACT}

Objective: Few data are available regarding the surgical strategies for an anomalous origin of the left coronary artery (LCA) from the right pulmonary artery (RPA) with an intramural aortic course. We reviewed our experience in a case series of 10 children.

Methods: From 2007 to 2014, 10 patients (7 boys and 3 girls, aged 3 months to 11 years, median 21 months) underwent surgical repair. Before the operation, echocardiography showed the mean left ventricular ejection fraction $45 \% \pm 10 \%$ and mean fractional shortening fraction $21 \% \pm 7 \%$. Moderate to severe mitral regurgitation was found in 4 patients and left ventricular aneurysm in 5 patients. The intramural aortic course of LCA was not diagnosed preoperatively in any of the patients.

Results: During the operation, the LCA orifice was seen and 2 types were identified: at the bifurcation of the main pulmonary artery and RPA in 3 patients, and more distal along the RPA from the bifurcation in 7 patients. In the first type, direct coronary button transfer was performed. In the second type, button transfer with unroofing of the intramural course was performed. Annuloplasty of the mitral valve was performed in 4 patients and the aneurysm was repaired with plication technique in 2 patients. Postoperatively, 2 patients died of cardiac failure. Others showed significantly improved left ventricular function at follow-up as compared with preoperative measures (mean ejection fraction $67 \% \pm 6 \%$, mean fractional shortening $32 \% \pm 3 \%, P=.01$ for both).

Conclusions: Careful attention should be paid to the extremely rare association of an aortic intramural course before and during an operation when dealing with anomalous LCA from the RPA. Surgical strategies for aortic reimplantation include coronary button transfer and unroofing of the intramural segment. The outcomes are encouraging. (J Thorac Cardiovasc Surg 2017;153:648-53)

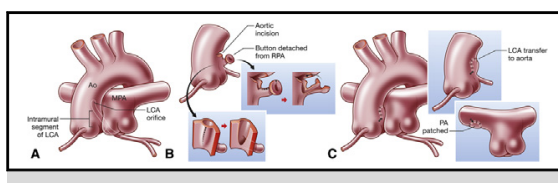

Operative illustrations of the button transfer and unroofing of intramural segment.

\section{Central Message}

We reviewed our surgical experience in a case series of 10 children with an anomalous origin of the left coronary artery from the right pulmonary artery with an intramural aortic course.

\section{Perspective}

Few data are available regarding the surgical strategies for an anomalous origin of the left coronary artery from the right pulmonary artery with an intramural aortic course. The case series of 10 children is the largest to date. Our surgical strategies included coronary button transfer with unroofing of the intramural segment, mitral annuloplasty, and plication of left ventricular aneurysm.

See Editorial Commentary page 654.
The most common anomaly of the anomalous left coronary artery (LCA) is from the main pulmonary artery (ALCAPA), or from the left or right pulmonary artery (RPA). This anomaly was first described anatomically in 1885 by Brooks ${ }^{1}$ and clinically in 1933 by Bland et al. ${ }^{2}$ ALCAPA is a rare congenital malformation, accounting for 1 in

From the Divisions of ${ }^{\mathrm{a}}$ Pediatric Cardiac Surgery and ${ }^{\mathrm{c}}$ Cardiac Anesthesiology, Children's Hospital affiliated to Capital Institute of Pediatrics; ${ }^{b}$ Division of Pediatric Cardiac Surgery, Anzhen Hospital; and ${ }^{\mathrm{d}}$ Clinical Physiology Research Center, Capital Institute of Pediatrics, Beijing, China.

Received for publication March 4, 2016; revisions received Sept 22, 2016; accepted for publication Oct 3, 2016; available ahead of print Dec 4, 2016.

Address for reprints: Jia Li, MD, PhD, Clinical Physiology Research Center, Capital Institute of Pediatric, Beijing, China 100020 (E-mail: j1al1@yahoo.com). $0022-5223 / \$ 36.00$

Copyright $₫ 2016$ Published by Elsevier Inc. on behalf of The American Association for Thoracic Surgery

http://dx.doi.org/10.1016/j.jtcvs.2016.10.063
300,000 live births and $0.25 \%$ to $0.5 \%$ of all congenital heart disease. ${ }^{3,4}$ It represents one of the most common causes of myocardial ischemia and infarction in children, and if left untreated, results in a mortality rate of up to $90 \%$ within the first year of life. ${ }^{5,6}$ Most ALCAPA cases present during infancy in the early months after birth, and approximately $20 \%$ of patients present in childhood or even as adults. $5,7,8$ Typically, LCA arises directly from the main pulmonary artery adjacent to the normal aortic origin as an isolated malformation. Rarely, it is from the

Scanning this QR code will take you to the article title page.

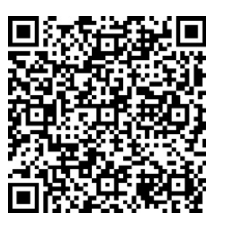




\section{Abbreviations and Acronyms}

ALCAPA $=$ anomalous left coronary artery from the pulmonary artery

LCA $=$ the left coronary artery

RPA $=$ the right pulmonary artery

RPA and can be associated with other congenital heart defects, such as ventricular septal defect, tetralogy of Fallot, and hypoplastic left heart syndrome. ${ }^{9-12}$ Even rarer is the association with an intramural aortic course but without other congenital heart defects. Such coronary anatomy requires special consideration for the surgical procedures to be selected. ${ }^{13}$ A review of the published data revealed isolated case reports and a small series of 4 cases. ${ }^{13-15}$ Therefore, we sought to review our diagnostic and surgical experience in a case series of 10 children.

\section{METHODS}

A retrospective chart review was conducted after the approval by the Institutional Health Research Ethics Board of Anzhen Hospital and Capital Institute of Pediatrics in Beijing, China. From 2007 to 2014, 46 children with ALCAPA underwent cardiac surgery for complete repair. Among them, 36 patients had the anomalous origin of LCA arising from the main pulmonary artery (14 cases from the right posterior sinus with 2 deaths, 20 from the left posterior sinus with 3 deaths, 2 from the left anterior sinus with 1 death). The remaining 10 patients had the aortic intramural
LCA arising from the RPA. Charts of 10 children ( 7 boys, 3 girls) of the latter anomaly group undergoing surgical repair at Anzhen Hospital were reviewed.

The patient characteristics are listed in Table 1 . The age of 10 patients ranged from 3 months to 11 years (median 21 months). The initial presentations included poor feeding, respiratory distress, and fussiness. Two of them (patients 2 and 3) were misdiagnosed as endocardial fibroelastosis. Electrocardiograms showed ischemic manifestations with Q-wave or/and T-wave inversion in I, AVL, and V5-6 leads.

The diagnosis was made predominantly from echocardiography $(\mathrm{n}=10)$, computed tomography $(\mathrm{n}=5)$, and coronary angiography $(\mathrm{n}=4)$. Echocardiography showed mean left ventricular ejection fraction of $45 \% \pm 10 \%$ and mean fractional shortening of $21 \% \pm 7 \%$. Severe mitral regurgitation was found in 4 patients (patients 2, 5, 6, and 10). The left ventricular aneurysm at apex was found in 5 patients (patients 2 , $5,7,8$, and 9) with the diameter ranging from 15 to $60 \mathrm{~mm}$. The intramural aortic course of LCA was not identified preoperatively in any of the patients.

\section{RESULTS}

\section{Surgical Techniques}

Cardiopulmonary bypass was established through median sternotomy with cannulation of aorta and the 2 caval veins. Hypothermia was maintained at $25^{\circ} \mathrm{C}$. Cardioplegic arrest was performed with antegrade cardioplegia to the aorta and main pulmonary artery with occlusion of the left and right pulmonary arteries to maintain sufficient pressure in the LCA and right coronary artery. The main pulmonary artery was incised, and the location of the orifice of ALCAPA was identified according to which 2 types were

TABLE 1. Clinical data in 10 patients

\begin{tabular}{|c|c|c|c|c|c|c|c|c|c|c|c|c|}
\hline $\begin{array}{c}\text { Patient } \\
\text { no. }\end{array}$ & Gender & $\begin{array}{l}\text { Age } \\
(\mathbf{m o})\end{array}$ & $\begin{array}{c}\text { Weight } \\
\text { (kg) }\end{array}$ & $\begin{array}{c}\text { Height } \\
(\mathrm{cm})\end{array}$ & $\begin{array}{l}\text { EF } \\
(\%) \\
\end{array}$ & $\begin{array}{l}\text { FS } \\
(\%) \\
\end{array}$ & $\begin{array}{c}\text { Mitral } \\
\text { regurgitation }\end{array}$ & $\begin{array}{c}\text { LV } \\
\text { aneurysm } \\
\left(\mathbf{m m}^{2}\right) \\
\end{array}$ & $\begin{array}{l}\text { CPB } \\
\text { time } \\
(\mathrm{min}) \\
\end{array}$ & $\begin{array}{c}\text { ACC } \\
\text { time } \\
(\min ) \\
\end{array}$ & $\begin{array}{c}\text { Surgical } \\
\text { techniques } \\
\text { (in addition to } \\
\text { button transfer) }\end{array}$ & $\begin{array}{c}\text { Death or } \\
\text { follow-up } \\
\text { period } \\
(\mathrm{mo}) \\
\end{array}$ \\
\hline 1 & Male & 3 & 5.5 & 56 & 45 & 22 & Mild & No & 326 & 118 & & Death \\
\hline 2 & Female & 21 & 8 & 78 & 56 & 29 & Severe & $30 \times 50$ & 192 & 115 & $\begin{array}{l}\text { MV annuloplasty, } \\
\text { aneurysm patch } \\
\text { repair }\end{array}$ & 72 \\
\hline 3 & Female & 8 & 5.9 & 62 & 45 & 22 & No & No & 178 & 95 & & 2 \\
\hline 4 & Male & 132 & 42 & 150 & 48 & 24 & No & No & 226 & 58 & Unroofing & 18 \\
\hline 5 & Male & 14 & 9 & 80 & 36 & 17 & Severe & $50 \times 60$ & 196 & 129 & $\begin{array}{l}\text { Unroofing, MV } \\
\text { annuloplasty } \\
\text { aneurysm patch } \\
\text { repair }\end{array}$ & Death \\
\hline 6 & Female & 28 & 11 & 89 & 45 & 22 & Severe & No & 123 & 59 & $\begin{array}{l}\text { Unroofing, MV } \\
\text { annuloplasty }\end{array}$ & 12 \\
\hline 7 & Male & 62 & 16.3 & 104 & 39 & 10 & No & $20 \times 20$ & 164 & 71 & $\begin{array}{l}\text { Unroofing, } \\
\text { aneurysmal } \\
\text { plication }\end{array}$ & 13 \\
\hline 8 & Male & 19 & 9.7 & 81 & 29 & 15 & Mild & $15 \times 15$ & 105 & 62 & & 5 \\
\hline 9 & Male & 21 & 12 & 94 & 47 & 23 & No & $20 \times 20$ & 148 & 68 & $\begin{array}{c}\text { Aneurysmal } \\
\text { plication }\end{array}$ & 72 \\
\hline 10 & Female & 6 & 5 & 61 & 64 & 32 & Severe & No & 111 & 62 & MV annuloplasty & 4 \\
\hline Mean \pm SD & & $31 \pm 39$ & $12 \pm 11$ & $85 \pm 27$ & $45 \pm 10$ & $22 \pm 6$ & & & $177 \pm 66$ & $84 \pm 27$ & & $25 \pm 30$ \\
\hline
\end{tabular}


classified. In the first type in 3 patients, the orifice of ALCAPA was at the bifurcation of the main pulmonary artery and RPA; in the second type in 7 patients, it was more distal along the RPA from the bifurcation. In both types, it gave rise to the bridging portion of the LCA between the RPA and aorta. The LCA then entered the aortic wall, forming the intramural segment of 3 to $5 \mathrm{~mm}$. It descended vertically in the aorta before emerging from the aortic wall over the left of the sinus of Valsalva to branch in the usual manner to supply the left ventricle. In the first type, the bridging portion of the LCA was relatively longer to allow sufficient mobilization. Reimplantation using a direct button transfer was performed. A horizontal incision was made at the left side of the ascending aorta at the same level of the LCA orifice. The collar of the button around the LCA orifice was made approximately $5 \mathrm{~mm}$ to allow sufficient tissue for anastomosis to the aorta incision and to form the "fish eye" shape to avoid tension or distortion of the LCA (Figure 1). In the second type, the bridging portion of the LCA was fairly short. The button transfer was combined with the unroofing technique, whereby the bridging portion of the LCA from the orifice and the aortic intima of the intramural segment were incised throughout and anastomosed with the horizontal incision of the ascending aorta (Figure 2). The incision of the aorta was directly closed. The incision of the main pulmonary artery was closed with a pericardial patch.

In 4 patients with severe mitral regurgitation, annuloplasty was performed with sutures at both commissures of the mitral valve. No repair was made in 2 patients with mild to moderate mitral regurgitation. Among the 5 patients with ventricular aneurysm, the first 2 patients with a large aneurysm $\left(30 \times 50 \mathrm{~mm}^{2}\right.$ in patient 2 , and $50 \times 60 \mathrm{~mm}^{2}$ in patient 5; Figure 3) had aneurysmal exclusion by closing the aneurysmal collar with a Dacron patch. One of them died of cardiac failure (patient 5). In the subsequent 2 patients (patients 7 and 9) with a small aneurysm $\left(20 \times 20 \mathrm{~mm}^{2}\right.$ for both), the aneurysm was longitudinally plicated without any incision and sutured using 3-0 Prolene with 2 small Dacron patches. No repair was made to the smallest ventricular aneurysm $\left(15 \times 15 \mathrm{~mm}^{2}\right)$ in patient 8 .

Cardiopulmonary bypass was maintained for $177 \pm 66$ minutes and aortic cross clamping for $84 \pm 28$ minutes.

\section{Patient Outcomes}

In the early postoperative period, 2 patients died of cardiac failure (patients 1 and 5). Patient 1 was our first patient. Patient 5 had the largest left ventricular aneurysm with a Dacron patch repair. Others had an uneventful recovery.

The follow-up period in the 8 survivors ranged from 2 months to 6 years (median 1 year). Echocardiography showed the mean left ventricular ejection fraction $67 \% \pm 6 \%$ and mean fractional shortening $32 \% \pm 3 \%$, significantly increased as compared with preoperative values ( $P=.01$ for both). Among the 4 patients who underwent mitral valve repair, mitral regurgitation became mild. Others did not show mitral regurgitation.

\section{DISCUSSION}

The present study reviewed our diagnostic and surgical experience in 10 children with an extremely rare association of congenital heart anomalies of ALCAPA arising from the RPA with an intramural course of the coronary artery. Our series, although a small cohort, is the largest series of children to date.

The incidence of ALCAPA arising from the RPA is substantial in our institute, accounting for $22 \%$ of all the ALCAPA cases during the study period. Importantly, all the 10 cases with such an anomaly were associated with an intramural aortic course but without other congenital heart defects. Reviewing the literature shows that the association has been described in many of the case reports of ALCAPA arising from RPA without other congenital heart defects, ${ }^{13-15}$ except a few ${ }^{16,17}$ that were reported from

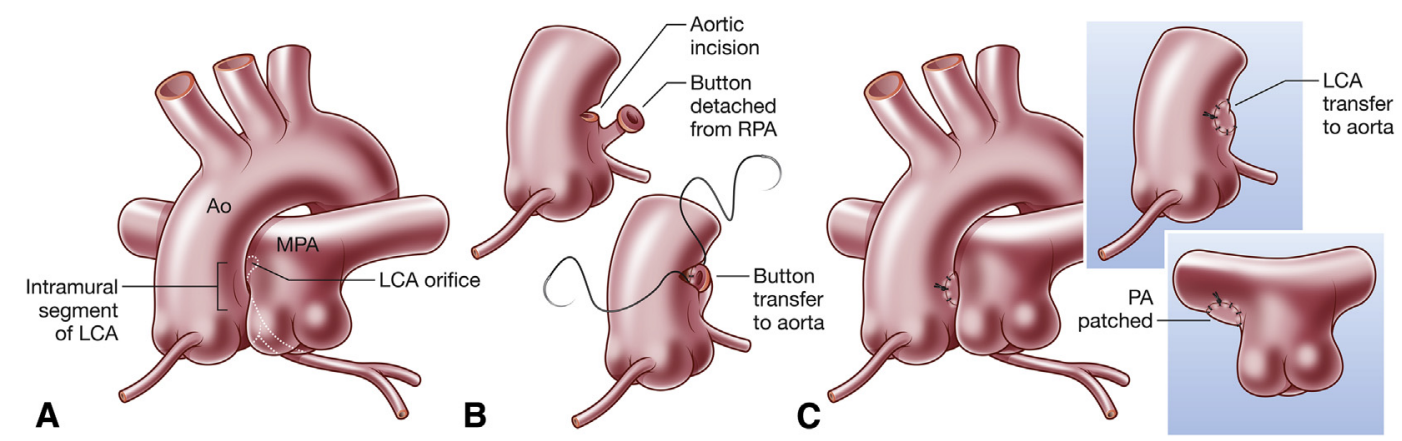

FIGURE 1. A, Anatomy of the anomalous origin of the LCA from the bifurcation of the right and MPA with the intramural aortic segment. B, Operative illustration of the button transfer showing a horizontal incision made at the left side of the ascending aorta at the same level of the LCA orifice with the collar of the button around the LCA orifice, which is detached and switched anteriorly. C, Operative illustration of anastomosis of the button to the aorta incision. $L C A$, Left coronary artery; $A o$, aorta; $M P A$, main pulmonary artery; $R P A$, right pulmonary artery. 

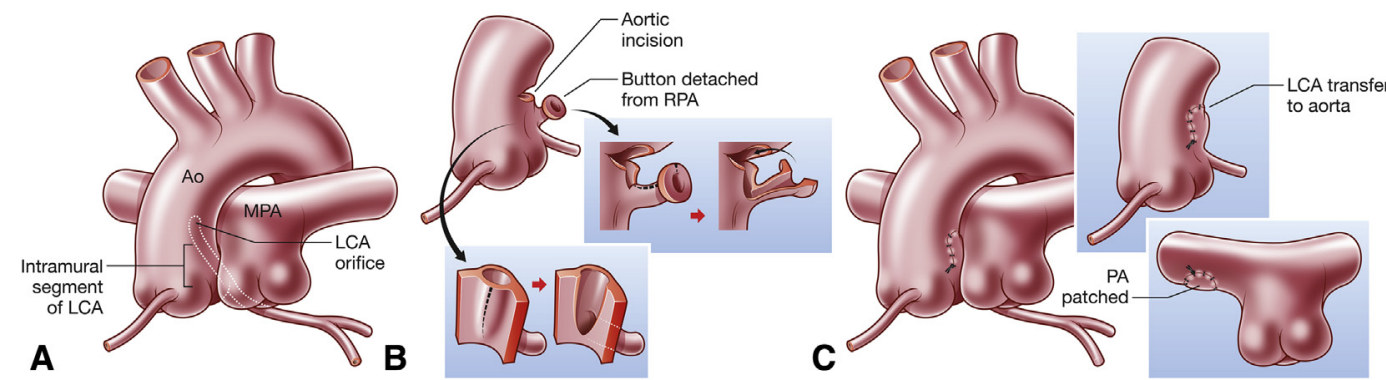

FIGURE 2. A, Anatomy of the anomalous origin of the LCA from the RPA more distal to the bifurcation with the intramural aortic segment. B, Operative illustrations showing that the short bridging portion of the LCA and the aortic intima of the intramural segment were incised. C, Operative illustrations of anastomosis of the button to the aorta incision. $L C A$, Left coronary artery; Ao, aorta; MPA, main pulmonary artery; RPA, right pulmonary artery.

earlier years, and the aortic intramural course might have been unnoticed. Of note, preoperative diagnosis of the intramural aortic course of the anomalous LCA is difficult. Similar to the report by Atik et al, ${ }^{15}$ all of our patients were diagnosed during the operation. As such, careful attention should be paid to the potential association of an aortic intramural course before the operation as well as during the operation when dealing with ALCAPA from the RPA.

Most ALCAPA cases present during infancy in the early months after birth, and approximately $20 \%$ of patients present in childhood or even as adults. ${ }^{5,7,8}$ It is generally considered that early diagnosis and surgical treatment are vital; if untreated, a mortality rate of up to $90 \%$ results within the first year of life. ${ }^{5,6}$ This is not exactly the case in our series. Most of our patients (7 of 10) presented after infancy from 14 months to 11 years old, and were complicated with congestive heart failure, mitral valve regurgitation, and left ventricular aneurysm. Their clinical manifestations, such as mitral regurgitation and left ventricular aneurysm, were not related to age, likely attributable to the varied degree of development of coronary collaterals. ${ }^{18,19}$ Should the collateral circulation be well developed and distributed, the left ventricle may remain well perfused, the heart retaining its essentially normal form and function. This may be the case in the 11-year-old patient (patient 4). In situations in which the collateral circulation is poorly developed, the left ventricle becomes ischemic, infracted, and fibrosed with mitral valvar incompetence, as happened to other patients.

Reimplantation to establish a 2-coronary arterial system is the standard technique for ALCAPA. ${ }^{20} \mathrm{~A}$ few cases of ALCAPA arising from the RPA have been reported to have undergone successful direct reimplantation. ${ }^{9,11,12}$
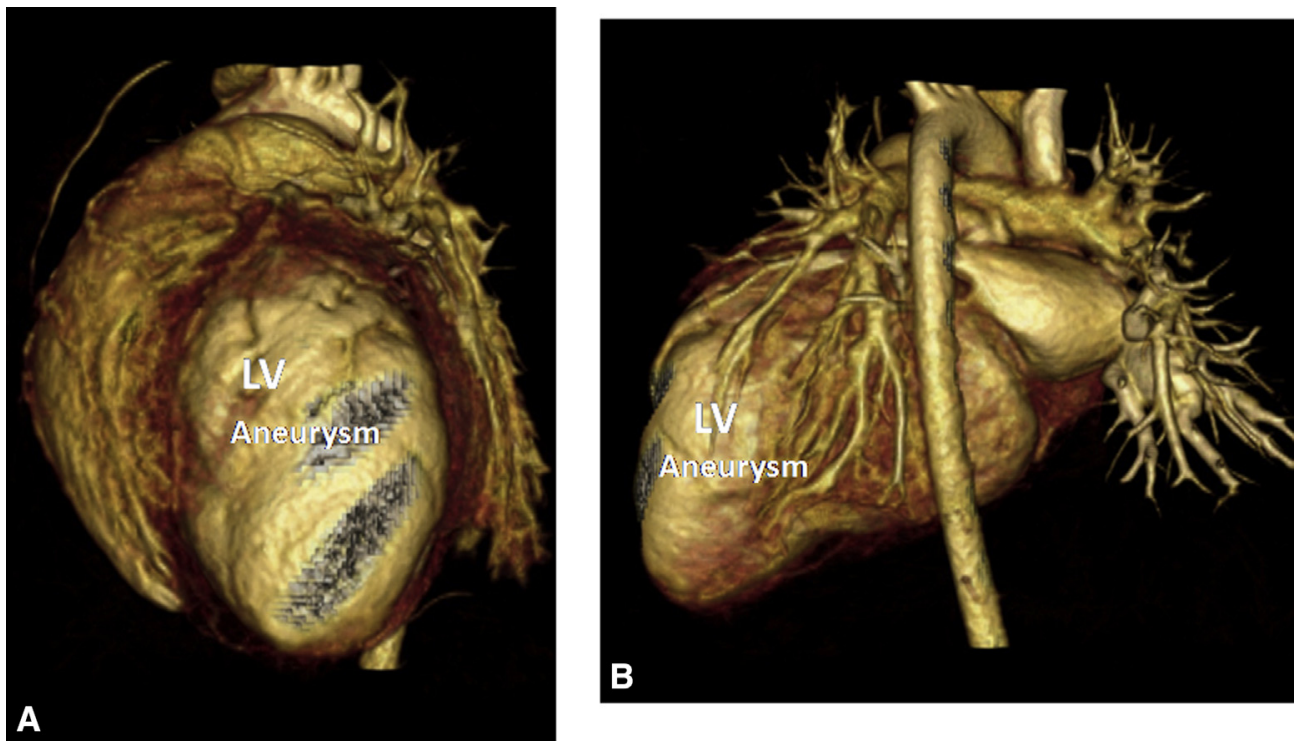

FIGURE 3. Two computed tomograms of apical view (A) and lateral view (B) showing the large LV aneurysm of $50 \times 60 \mathrm{~mm}^{2}$ in Patient No. $5 . L V$, Left ventricular. 
Direct reimplantation with button transfer of the LCA orifice was performed in all the patients in our series. In the 3 patients with the LCA arising at the bifurcation of the main pulmonary artery and RPA, the bridging portion was relatively longer and sufficient to allow extensive mobilization of the LCA. In these patients, only direct button transfer was performed, leaving the intramural segment untouched. However, the intramural coronary artery is known to pose potential risks of myocardial ischemia and even sudden death. ${ }^{21,22}$ In the 7 patients with the orifice of LCA located higher at the RPA, the limited length of bridging portion may pose the risks of tension or distortion of the LCA. Unroofing of the bridging portion of the LCA and intramural aortic segment was performed to extend the neo-orifice of the LCA. ${ }^{13}$ The combination of button transfer and unroofing procedure largely normalizes an entire course of the LCA without leaving the intramural segment and allows wider orifice of the LCA. Therefore, we consider the combination of button transfer and unroofing procedure is superior to button transfer alone, as well as to the previously advocated unroofing alone. ${ }^{13}$

The management of the regurgitant mitral valve at the time of ALCAPA repair has raised some controversy. ${ }^{23,24}$ Although some suggest that mitral regurgitation should be repaired at the time of coronary transfer, ${ }^{25}$ most believe that mild to moderate regurgitation will improve with the improved left ventricular function after coronary transfer. We, like others, ${ }^{24,26-28}$ advocate mitral valve repair only for severe mitral regurgitation in the setting of ventricular dysfunction.

Little has been reported about the association of ALCAPA and left ventricular aneurysm resulting from infarction. ${ }^{29}$ This is surprising to us, because 5 of 10 patients had a left ventricular aneurysm in our series. In the first 2 patients (patients 2 and 5) with large left ventricular aneurysm, aneurysm exclusion was performed by closing the aneurysmal collar with a Dacron patch, which severely affected left ventricular function. One patient died of cardiac failure early after the operation (patient 5). Since then, the "nopatch" technique was used with plication of the scar tissue. ${ }^{30}$ Similar technique has been used for the Ebstein anomaly with repair with longitudinal plication of the atrialized chamber and the right atrium to reconstruct the right ventricle and reduce the size of the dilated right atrium. ${ }^{31,32}$ This technique used for the repair of left ventricular aneurysm in ALCAPA features several major advantages; namely, not having a ventricular incision, saving cardiopulmonary bypass time, and, more importantly, reestablishing a physiological-like ventricular function and morphology closest to the one before myocardial infarction.

In the 8 survivors, the left ventricular function improved remarkably at follow-up, consistent with previous reports. ${ }^{14,15,33-35}$

\section{Limitations}

The follow-up period was fairly short in our patients, which is a general problem in current Chinese clinical practice in pediatric cardiology and surgery.

\section{CONCLUSIONS}

Careful attention should be paid to the extremely rare association of an aortic intramural course before and during an operation when dealing with the anomalous LCA from RPA. Surgical strategies for the associated anomalies include coronary button transfer or/and unroofing technique and provide encouraging outcomes. Coronary button transfer combined with unroofing of the intramural segment is recommended because it allows a more secured perfusion of the LCA without leaving risks of myocardial ischemia imposed by the intramural course.

\section{Conflict of Interest Statement}

Authors have nothing to disclose with regard to commercial support.

We are grateful to Professor Igor E. Konstantinov from the Royal Children's Hospital in Melbourne for providing precise surgical technique illustrations for this article.

\section{References}

1. Brooks HS. Two cases of an abnormal coronary artery of the heart arising from the pulmonary artery: with some remarks upon the effect of this anomaly in producing cirsoid dilatation of the vessels. J Anat Physiol. 1885;20: 26-9.

2. Bland EF, White PD, Garland J. Congenital anomalies of the coronary arteries: report of an unusual case associated with cardiac hypertrophy. Am Heart J. 1933; 8:787-801.

3. Pena E, Nguyen ET, Merchant N, Dennie C. Alcapa syndrome: not just a pediatric disease. Radiographics. 2009;29:553-65.

4. Greenberg MA, Fish BG, Spindola-Franco H. Congenital anomalies of the coronary arteries. Classification and significance. Radiol Clin North Am. 1989;27: 1127-46.

5. Wesselhoeft H, Fawcett JS, Johnson AL. Anomalous origin of the left coronary artery from the pulmonary trunk. Its clinical spectrum, pathology, and pathophysiology, based on a review of 140 cases with seven further cases. Circulation. 1968;38:403-25.

6. Keith JD. The anomalous origin of the left coronary artery from the pulmonary artery. Br Heart J. 1959;21:149-61.

7. Zheng J, Ding W, Xiao Y, Jin M, Zhang G, Cheng P, et al. Anomalous origin of the left coronary artery from the pulmonary artery in children: 15 years experience. Pediatr Cardiol. 2011:32:24-31.

8. Rajbanshi BG, Burkhart HM, Schaff HV, Daly RC, Phillips SD, Dearani JA. Surgical strategies for anomalous origin of coronary artery from pulmonary artery in adults. J Thorac Cardiovasc Surg. 2014;148:220-4.

9. Tanaka SA, Takanashi Y, Nagatsu M, Ohta J, Hoshino S, Imai Y. Origin of the left coronary artery from the right pulmonary artery. Ann Thorac Surg. 1996;61: 986-8.

10. Bitar FF, Kveselis DA, Smith FC, Byrum CJ, Quaegebeur JM. Double-outlet right ventricle (tetralogy of fallot type) associated with anomalous origin of the left coronary artery from the right pulmonary artery: report of successful total repair in a 2-month-old infant. Pediatr Cardiol. 1998;19:361-2.

11. Sarris GE, Drummond-Webb JJ, Ebeid MR, Latson LA, Mee RB. Anomalous origin of left coronary from right pulmonary artery in hypoplastic left heart syndrome. Ann Thorac Surg. 1997;64:836-8.

12. Levin SE, Dansky R, Kinsley RH. Origin of left coronary artery from right pulmonary artery co-existing with coarctation of the aorta. Int J Cardiol. 1990;27: 31-6. 
13. Adachi I, Kagisaki K, Yagihara T, Hagino I, Ishizaka T, Kobayashi J, et al. Unroofing aortic intramural left coronary artery arising from right pulmonary artery. Ann Thorac Surg. 2008;85:675-7.

14. Turley K, Szarnicki RJ, Flachsbart KD, Richter RC, Popper RW, Tarnoff H. Aortic implantation is possible in all cases of anomalous origin of the left coronary artery from the pulmonary artery. Ann Thorac Surg. 1995;60: 84-9.

15. Atik E, Barbero-Marcial M, Tanamati C, Kajita L, Ebaid M, Jatene A. Anomalous origin of the left coronary artery from the right pulmonary artery with intramural aortic trajectory. Clinicosurgical diagnostic implications. Arq Bras Cardiol. 1999;73:181-90.

16. Doty DB, Chandramouli B, Schieken RE, Lauer RM, Ehrenhaft JL. Anomalous origin of the left coronary artery from the right pulmonary artery. J Thorac Cardiovasc Surg. 1976;71:787-91.

17. Hamilton JR, Mulholland HC, O'Kane HO. Origin of the left coronary artery from the right pulmonary artery: a report of successful surgery in a 3-monthold child. Ann Thorac Surg. 1986;41:446-8.

18. Edwards JE. Anomalous coronary arteries with special reference to arteriovenous-like communications. Circulation. 1958;17:1001-6.

19. Edwards JE. The direction of blood flow in coronary arteries arising from the pulmonary trunk. Circulation. 1964;29:163-6.

20. Backer CL, Stout MJ, Zales VR, Muster AJ, Weigel TJ, Idriss FS, et al. Anomalous origin of the left coronary artery. A twenty-year review of surgical management. J Thorac Cardiovasc Surg. 1992;103:1049-57; discussion $57-8$.

21. Kragel AH, Roberts WC. Anomalous origin of either the right or left main coronary artery from the aorta with subsequent coursing between aorta and pulmonary trunk: analysis of 32 necropsy cases. Am J Cardiol. 1988;62: $771-7$.

22. Mustafa I, Gula G, Radley-Smith R, Durrer S, Yacoub M. Anomalous origin of the left coronary artery from the anterior aortic sinus: a potential cause of sudden death. Anatomic characterization and surgical treatment. J Thorac Cardiovasc Surg. 1981;82:297-300.

23. Lambert V, Touchot A, Losay J, Piot JD, Henglein D, Serraf A, et al. Midterm results after surgical repair of the anomalous origin of the coronary artery. Circulation. 1996;94:II38-43.

24. Alexi-Meskishvili V, Hetzer R, Weng Y, Lange PE, Jin Z, Berger F, et al. Anomalous origin of the left coronary artery from the pulmonary artery. Early results with direct aortic reimplantation. J Thorac Cardiovasc Surg. 1994;108: 354-62.
25. Isomatsu Y, Imai Y, Shin'oka T, Aoki M, Iwata Y. Surgical intervention for anomalous origin of the left coronary artery from the pulmonary artery: The Tokyo experience. J Thorac Cardiovasc Surg. 2001;121:792-7.

26. Backer CL, Hillman N, Dodge-Khatami A, Mavroudis C. Anomalous origin of the left coronary artery from the pulmonary artery: successful surgical strategy without assist devices. Semin Thorac Cardiovasc Surg Pediatr Card Surg Апnи. 2000;3:165-72.

27. Huddleston CB, Balzer DT, Mendeloff EN. Repair of anomalous left main coronary artery arising from the pulmonary artery in infants: long-term impact on the mitral valve. Ann Thorac Surg. 2001;71:1985-8; discussion 8-9.

28. Monge MC, Eltayeb O, Costello JM, Sarwark AE, Carr MR, Backer CL. Aortic implantation of anomalous origin of the left coronary artery from the pulmonary artery: long-term outcomes. Ann Thorac Surg. 2015;100:154-60; discussion 60-1.

29. Grotenhuis HB, Backx A, Nijveld A. Resection of a cardiac aneurysm in an infant with anomalous origin of the left coronary artery from the pulmonary trunk. Car diol Young. 2004;14:106-8.

30. Evora PR, Bassetto S, Junior LA. A variant "no-patch" technique for surgery of left ventricular aneurysms. Asian Cardiovasc Thorac Ann. 2014;22: 242-4.

31. Yamagishi M, Fujiwara K, Itoh K, Wada Y, Kitamura N. Oblique plication for repair of the atrialized ventricle and tricuspid incompetence of Ebstein's anomaly. Jpn J Thorac Cardiovasc Surg. 2000;48:115-7.

32. Nguyen HS, Vu TD, Nguyen TQ. Modified carpentier's technique for Ebstein's anomaly repair. J Card Surg. 2014;29:554-60.

33. Dodge-Khatami A, Mavroudis C, Backer CL. Anomalous origin of the left coronary artery from the pulmonary artery: collective review of surgical therapy. Ann Thorac Surg. 2002;74:946-55.

34. Ando M, Mee RB, Duncan BW, Drummond-Webb JJ, Seshadri SG, Igor Mesia CI. Creation of a dual-coronary system for anomalous origin of the left coronary artery from the pulmonary artery utilizing the trapdoor flap method. Eur J Cardiothorac Surg. 2002;22:576-81.

35. Naimo PS, Fricke TA, d'Udekem Y, Cochrane AD, Bullock A, Robertson T, et al Surgical intervention for anomalous origin of left coronary artery from the pulmonary artery in children: a long-term follow-up. Ann Thorac Surg. 2016;101: 1842-8.

Key Words: surgery, anomalous origin of the left coronary artery, intramural aortic course 